\title{
LA MÍSTICA Y SUS INDICACIONES FORMALES PARA EL PENSAR. SAN AGUSTÍN EN EL II HEIDEGGER ${ }^{1}$
}

\author{
José Manuel Chillón Lorenzo \\ https://orcid.org/0000-0002-7755-7849 \\ Universidad de Valladolid \\ https://doi.org/10.15304/ag.40.1.6684
}

\section{Resumen}

La influencia de San Agustín en la analítica existencial de Ser y Tiempo goza de un alto reconocimiento y es siempre fuente de fecundas investigaciones. Nuestro trabajo, sin embargo, tratará de descubrir la sombra alargada del obispo de Hipona en la definición de la tarea del pensar, y por tanto en el II Heidegger, desde lo que denominaremos la salvación del momento vital-existencial de la experiencia del encuentro con el absoluto. Se investiga aquí, entonces, la posibilidad de que en las Confesiones se muestren las notas fundamentales en las que, en nuestra opinión, se funda la experiencia mística (la distancia del hombre respecto de las cosas, la relativización de los asuntos mundanos y el olvido de sí) para servir como indicadores formales de lo que sea la noción heideggeriana del pensar meditativo, del pensar que nos queda.

Palabras clave: mística, teología, ser, pensamiento, Agustín, Heidegger.

\section{Abstract}

The influence of Saint Augustine in the existential analysis of Being and Time is highly recognized and is always a source of fruitful research. Our work, however, will try to discover

Recibido: 23/03/2020. Aceptado: 30/06/2020.

${ }^{1}$ Este artículo se enmarca dentro del Proyecto de Investigación del Ministerio Español sobre la filosofía de Heidegger cuya referencia es PID2019-108291GB-I00. 
the elongated shadow of the bishop of Hippo in the definition of the task of thinking, and therefore in II Heidegger, from what we will call the salvation of the vital-existential moment of the experience of the encounter with the absolute. It is investigated here, then, the possibility that the fundamental notes on which, in our opinion, the mystical experience that is inferred in the Confessions (the distance of man from things, the relativization of worldly affairs and the self-forgetfulness) can count as formal indicators of what is the heideggerian notion of meditative thinking.

Keywords: mysticism, theology, being, thinking, Augustine, Heidegger.

\section{Mística y pensamiento ${ }^{2}$}

La comprensión del pensar del último Heidegger culmina su propuesta crítica de filosofar lejos de los presupuestos de la modernidad que encuentra su apoteosis en la metafísica consumada de la técnica. Más allá del pensar reo de la voluntad y solidario de la dominación y de la Machenschaft, queda el otro pensar que ya no sólo niega la rotundidad del filosofar occidental, sino que, para no caer en sus redes, abandona su modo de decir y de hacer ${ }^{3}$. Aquel pensar que cedió los derechos del ser a los entes en una comprensión del mismo desde las nociones de idea, sustancia y esencia, entre otras, terminó subordinando todo al logos humano, a la hechura de la actividad de la conciencia y de la voluntad que preforma y constituye todo sentido de lo real, desde Descartes a Husserl, pasando por Nietzsche ${ }^{4}$.

${ }^{2}$ Agradezco la sugerente idea del profesor Emilio J. Justo para publicar este texto a la luz del trabajo de González de Cardedal, O., Cristianismo y mística, Madrid, Trotta, 2015.

${ }^{3}$ Según el trabajo de R. Capobianco, "El Sein había sido ampliamente olvidado con su viraje hacia el Sinn, lo cual hizo resurgir la Seinsfrage de una manera importante y urgente. Para superar esta preocupación por lo noético de la filosofía moderna y contemporánea, se vio resuelto a traer nuevamente a cuenta el pensar y el poetizar, por medio de un rescate de la experiencia griega, "la manifestación del ser" o "la verdad del ser" (...) El ser precede estructuralmente y excede el sentido. Ser es irreductible al sentido". Capobianco, R., La vía del ser de Heidegger, Madrid, Guillermo Escolar, 2020, p. 20.

${ }^{4}$ El nihilismo de Nietzsche, que trataba de instaurar el tiempo nuevo de los hombres superiores en el que la renuncia al trasmundo socrático-platónico pondría patas arriba los valores previamente invertidos por los débiles, también cuenta entre los rendimientos, ya no de la subjetividad de la conciencia, sino de la voluntad. El mismo que en Sobre verdad $y$ mentira en sentido extramoral denunciaba el hecho del conocimiento como el momento más altanero de la historia, hablaba por boca de la misma subjetividad. Es verdad que el de Röcken filosofaba contra toda una voluntad de verdad responsable de la farsa de la moral y de la cultura occidentales, pero lo hacía poniendo en valor, aunque apodada de otra manera, esa misma voluntad. De modo que, lo que se problematiza desde el análisis heideggeriano tanto en Nietzsche I, como en Nietzsche II (GA 6.1 y GA 6.2) no es el resultado del ejercicio de la voluntad sino el propio ejercicio, la propia actividad creadora, poderosa, impositiva, 
La tesis que se mantiene en este artículo es que este giro en la comprensión del quehacer de la filosofía y de la tarea del pensar tiene algunos de sus rudimentos en las aportaciones fenomenológico-hermenéuticas de la experiencia religiosa, en este caso de las Confesiones de san Agustín, a las que Heidegger, en sus primeros años, les concede una importancia decisiva. Se trata, entonces, de poner a Agustín como modelo de trabajo de una transformación, y por tanto de una cierta Kehre que, en nuestra opinión, parece haber acontecido en Heidegger casi en paralelo a la que sucedió en su filosofía: de la consideración de la vivencia religiosa como ejemplo de experiencia fenomenológica (para lo cual toma no sólo a Agustín sino también al cristianismo primitivo de las epístolas paulinas), a la dimensión místico espiritual que adquiere su comprensión de la tarea del pensar y del quehacer de la filosofía en este tiempo inclemente. La lectura atenta y minuciosa de la obra del obispo de Hipona, y en especial, como decimos, de las Confesiones, quizá pudo servir en su momento para ir dejando un cierto poso que justificaría, después, cómo la experiencia renovadora del pensar tiene, ya en el II Heidegger, ciertos parecidos de familia con aquella transformación existencial del hombre que, descubriéndose en relación con el absoluto, se sabe en el camino de la verdad ${ }^{5}$.

¿Es, entonces, la dinámica de lo religioso la mejor manera de entenderse a sí mismo desde la finitud y desde la relatividad que se asumen exactamente al tiempo que se advierte la infinitud de lo absolutamente Otro? ¿Es la mística, primero cristiana y luego de tradición oriental ${ }^{6}$, el emblema del pensar que ante todo renuncia a lo positivo del tener que decir, del estar obligado a producir, del dar fundamento a todo dominar? En definitiva, ¿podrá salvarse el momento religioso sin la confesionalidad de credo alguno (que, en el fondo, es lo que significa la experiencia mística) para descubrir ahí la potencia de un pensar que, desde la vivencia del abandono, de la renuncia,

señorial, totalizante y dominadora. Así las cosas, el nihilismo tenía que ser el destino de toda la metafísica.

${ }^{5}$ No es que Heidegger ya no volviera directamente sobre Agustín, buena muestra fue el Seminario sobre el concepto de tiempo a raíz del capítulo XI de las Confesiones recogido en GA 83 con su insistencia en la importancia de las concepciones de la facticidad y de la temporalidad. No nos referiremos en este trabajo a esta influencia suficientemente estudiada y reconocida por la comunidad académica. Nos interesa ahora, como decimos, la impronta de lo que en Agustín es la experiencia religiosa en la nueva comprensión que, después de la Kehre, Heidegger tiene del Dasein, del ser y del pensar en sus resonancias místico-espirituales.

${ }^{6}$ No nos dedicamos aquí a la exposición concreta de los aspectos y relaciones del II Heidegger y de la mística oriental para cuyo análisis remitimos al original y sugerente trabajo de Salviani, C., El oriente de Heidegger, Barcelona, Herder, 2004. 
de la dejación de los haberes del mundo, pueda volverse a sí, tenga la oportunidad de descubrirse a sí, una vez suspendida la potencia insurrecta de la voluntad? ¿Qué tiene, en definitiva, todo el conglomerado religioso para que seduzca tanto al filosofar de Heidegger a pesar de que se pueda discutir hasta dónde alcanza esa influencia, si es sólo formal o es determinante de su pensar hasta llegar incluso a ser considerada su filosofía como un tipo de teología secularizada? En nuestra opinión, sus estudios teológicos y sus primeros intereses intelectuales proyectan una larga sombra sobre su obra. Esas primeras motivaciones, sostiene el propio Heidegger, explicarían la deriva de su propio pensar ${ }^{7}$. Y aunque de ello no pueda deducirse el extremo de afirmar que su filosofía sea un tipo de teología sin un Dios confesado, creemos que merece la pena, desde el punto de vista histórico y sistemático, desentrañar esto que hemos denominado la impronta religiosa del pensar heideggeriano ${ }^{8}$.

La caracterización de la tarea del pensar del último Heidegger, esta es nuestra tesis, nos invita a presuponer que aquí hay todavía una huella de aquella experiencia religiosa que tanta importancia tuvo en sus primeros trabajos hermenéutico-fenomenológicos. No en vano, la contemplación propia de lo místico (que no tiene que ver nada, advierte Heidegger, con el alejamiento autista del mundo) en cuanto supone "toda agitación del espíritu sustraída a efectividad externa", ${ }^{9}$ invita a un descenso a la interioridad, a una vuelta hacia sí mismo, a un descubrimiento de uno mismo a expensas de todo lo otro ${ }^{10}$. ¿No fue esta la llamada de Agustín? De eso va lo que aquí llamamos salvar el momento vital-existencial de lo religioso: de descubrir que, según nuestra interpretación, esas experiencias de totalidad,

7 "Sin este origen teológico, nuca hubiera alcanzado el camino del pensar". Heidegger, De camino al habla, p. 95.

${ }^{8}$ Cfr. J.M. Chillón: "Ser en el mundo sin ser del mundo. Serenidad y direcciones del cuidado en Heidegger”, Pensamiento, vol. 74, 2018, pp. 661-680; Serenidad. Heidegger para un tiempo postfilosófico, Granada, Comares, 2019.

${ }^{9}$ M. Heidegger, Estudios sobre mística medieval, México, FCE, 2014, p. 175.

${ }^{10}$ De hecho, en La pregunta por la técnica vuelve sobre aquel problema: "Sin embargo, la verdad es que hoy el hombre no se encuentra en ninguna parte consigo mismo, es decir, con su esencia". Pensar va a ser esa oportunidad del hombre para poder encontrarse y saberse. Son muy pocas, sin embargo, las posibilidades que el hombre tiene ahora para pensar ya que el tiempo del desocultar provocador, al extender sus modos de consideración de la realidad desde la imposición técnica, termina considerando todo como un objeto, toda verdad como aquello que se muestra y se agota en su desocultamiento sin lugar para hacerse cargo de aquello oculto en donde radica la posibilidad del misterio como oportunidad para la meditación. Cfr. Heidegger, M., "La pregunta por la técnica" en Conferencias y artículos, Barcelona, Serbal, 2001, pp. 9-37. 
esa remoción íntegra de la persona ante Dios pudo servir como paradigma de la profundidad a la que se refiere Heidegger con el pensar como tarea que surge ahora, cuando la filosofía alcanza su fin.

El cara a cara ante el misterio de la existencia, el vivir cabe el absoluto, el encuentro con la finitud del ente que se sabe a la sombra del Otro, la experiencia de la dependencia ${ }^{11}$ o la inefabilidad ante lo trascendente, pudieron orientar a Heidegger para pautar lo que significa el pensar como quehacer por medio del cual, este ente que somos, se sabe a la sombra del ser para que a su luz aparezcan los entes. Se abre aquí la dimensión del pensar como aquella experiencia ante la que se queda corto todo decir apofántico, toda lógica y toda metafísica ${ }^{12}$.

Ante el absoluto, ante lo divino, el ser humano puede descubrir experiencias de plenitud, de entrega y de radicalidad, pero también de ausencia y de falta. La tradición mística habla más de esta segunda faz: más de búsqueda que de encuentro, más de pérdida que de hallazgo, más de abandono que de realización personal. En esta nada de la incertidumbre que se acompasa siempre con la primera certeza de la fe, en esta sensación de pérdida de fundamento que abisma la existencia, en esta subida dolorosa al monte cuya cumbre está siempre más lejos de lo que el alma alcanza, en este clamor desolado en el que queda el amor que busca al amado huido, pudo haber encontrado Heidegger las notas de este otro pensar indigente. Y como la mística constituye, según Heidegger, un contramovimiento elemental ${ }^{13}$, nuestra interpretación es que quizá lo que significó para la fe soportar la existencia en un tiempo inclemente, pudo servir como modelo de resistencia para poder soportar, ahora, el tiempo del nihilismo. Esta idea sobre la que

${ }^{11}$ El ser humano es dependiente de la verdad si la verdad es propiamente entendida como el iluminar del Seyn ya que depender significa estar determinado y totalmente sintonizado en esencia, pero no causado. Cfr. M. Heidegger, GA 88, Frankfurt, Vittorio Klostermann, 2008, p. 205.

12 "La filosofía en cuanto disciplina separada de la vida es impotente; la mística en cuanto vivencia irracional carece de rumbo, no tiene fin". Esto había explicado Heidegger en su trabajo de habilitación sobre Duns Scotto para advertir, quizá, de la novedad de la hermenéutica de la facticidad en cuanto giro transformador de la fenomenología. Si es así, la mística que luego sustenta el otro pensar, deberá tener otros elementos distintos a una mera dejación de la experiencia al sentimiento. Una experiencia que, más que descubrirse impensable desde los fundamentos filosóficos de occidente, está constatando críticamente los intentos de aquel pensar lógico-productivo-calculador de presentarse como el único modo de razonamiento. "Philosophie als vom Leben abgelöstes, rationalistisches Gebilde ist machtlos, Mystik als irrationalistisches Erleben ist ziellos”. M. Heidegger, Die Kategorien und Bedeutungslehre des Duns Scotus, GA 1, Frankfurt, Vittorio Klostermann, 1978, pp. 189-412, p. 410.

${ }^{13}$ Cfr. Heidegger, Estudios sobre mistica medieval, p. 169. 
volveremos después, no pasa de ser una posible lectura, evidentemente con menos peso específico que la otra propuesta de este trabajo ya avanzada antes: el hallazgo de indicaciones formales en el análisis fenomenológicohermenéutico de la experiencia religiosa no sólo para la analítica existencial (algo de sobra conocido y asumido por la comunidad académica) sino también para la experiencia del pensar.

Esta experiencia del pensar meditativo (besinnliche Nachdenken) desde los presupuestos de la experiencia mística termina advirtiéndonos, en nuestra opinión, de que somos mucho menos de lo que nos creemos, precisamente por ser más de lo que pensamos ${ }^{14}$. Por eso, volver al ser humano, rescatarlo de la extravagante posición en la que ha quedado desde la lógica del filosofar de la modernidad, obliga a un cambio de rumbo (ya sea en el modo fenomenológico del poner entre paréntesis, ya sea en la propuesta genuina del paso atrás, del giro o del salto) para comprender, como nunca antes, que sólo a la luz del ser (o a la sombra del absoluto), este ente que somos cada uno de nosotros encuentra una centralidad que ya no es la del humanismo heredero de la metafísica, sino la de la relatividad de la existencia.

\section{Pablo y Agustín. Fenomenología de la experiencia cristiana en dos horizontes}

Pablo y Agustín responden a tiempos diferentes y a motivaciones distintas, pero ellos, que representan dos grandes épocas del cristianismo, escriben para plantear el problema de cómo vivir la fe en la intemperie de la increencia, la cuestión acerca de cómo soportar la existencia cristiana en un mundo que constantemente tienta a abandonarse en él, la compleja tarea de resolver cómo compatibilizar esos dos amores que pertenecen a la paradójica experiencia humana: el amor a Dios y el amor al mundo.

Cuando irrumpe la fe, ¿cómo resultan transformadas todas las dimensiones humanas? ¿Cómo queda el hombre cuando se sabe coram Deo? ¿Cómo se puede captar esa apertura y pensar esa trascendencia? ¿Tiene que ver lo religioso más con la racionalidad, con la deducción, con una especie de rec-

${ }^{14}$ El propio Tugendhat, E., Egocentricidad y mística, Barcelona, Gedisa, 2004, habría añadido que la mística es el modelo de distanciamiento radical, no relativo, de sí mismo, del propio yo. Quizá se abra aquí una línea de investigación consistente en advertir cuán lejos está el egocentrismo inauténtico y el ensimismamiento al que nos conduce el tiempo de la técnica y de la maquinación, del ideal de sabiduría del epimelia autou, del cuidado de sí (Conf. X, 43, 70). En Agustín, el homo interior termina "arrojando en Dios su cuidado" porque solo Dios conoce la impericia, la debilidad y la vulnerabilidad de lo humano. Agustín de Hipona, Confesiones, Madrid, Biblioteca de Autores Cristianos, 1996. En adelante Conf. 
ta conducción del pensar o, por el contrario, la experiencia religiosa requiere de otras capacidades distintas? Desde la vivencia del kairós cristiano de la parousía ya próxima, desde esa vivencia de la tensión escatológica, como creen los de Tesalónica, pasando por la transformación radical de la existencia que se descubre abandonada y arrojada tanto como sostenida por la gracia en Agustín, hasta el desasimiento en que se halla el hombre cuando se deja inundar por el que lo es todo en Eckhart, la cuestión es la misma: cómo la experiencia de la fe transforma al hombre llamado, entonces, a transformar el mundo. La experiencia religiosa, al poner en juego no un aspecto accidental de la existencia, sino la existencia toda, al tener que volverse a sí para convertirse de las actitudes mundanas que terminan anulando la referencia del hombre a Dios, al desnudar su fragilidad y pequeñez ${ }^{15}$ no solo desde la contingencia metafísica del que se descubre siendo ab alio, sino del ser humano y su conciencia de finitud, pudo ofrecer a Heidegger la pauta que le sirvió de guía de lo que significó la experiencia del pensar.

Se trata, entonces, de encontrar en la vivencia religiosa algún tipo de indicaciones formales que permitan explicitar lo que se quiere decir con este pensar pensante, meditativo. Y quizá, aunque esto exigiría una discusión más profunda, según hemos avanzado ya, entender la propuesta del Heidegger de la Kehre como una invitación a mantener vivo el pensar ${ }^{16}$, a resistir a la tentación de plegar el pensamiento a los dictados de esa voluntad de voluntad mediante una llamada a la interioridad en la que pueden percibirse aquellas resonancias místico espirituales que recuerdan cómo la experiencia religiosa como vivencia interior, desde Agustín, supuso también una forma de soportar la indigencia.

El cristianismo primitivo es para Heidegger un saber ejemplar por representar un modelo de pensar alternativo al modo de comprensión puramente teórico. Y esto es lo que sirve a la transformación fenomenológica que se estaba inaugurando en los años 20: descubrir la riqueza de una fe que, en

${ }^{15}$ A los ojos de Dios "siempre está desnudo el abismo de la conciencia humana". Conf. $\mathrm{X}, 2,2$.

${ }^{16}$ Y por tanto esta investigación, aun en la línea de las propuestas innovadoras de Caputo en The mystical element in Heidegger's thought, New York, Fordham University Press, 1986 o de trabajos como los de Cappelle Dumont en Filosofía y teología en el pensamiento de M. Heidegger, México, FCE, 2012, por nombrar solo algunas, no quiere tanto explicitar esos elementos místicos en Heidegger cuanto poner de manifiesto cómo aquella primera motivación teológica se mantuvo siempre en el horizonte de su filosofía y, sobre todo, cómo la experiencia de la mística, en tanto reacción a un mundo en el que Deus est semper absconditus, posee las claves de lo que después se denominó el pensamiento del ser que solo puede tomar la forma de una meditación. 
la línea de Pablo, Agustín, Lutero y Kierkegaard (y, en suma, de la teología protestante renovada por la teología dialéctica de Barth) dejaba de tener motivaciones psicológicas y explicaciones cognoscitivo-intelectuales, para pasar a contener rendimientos existenciales y ontológicos de primer orden. Resumamos, pues, los aspectos fundamentales del análisis heideggeriano de las epístolas paulinas donde, como se sabe bien, encuentra el de Messkirch indicaciones formales de lo que sea la facticidad (como el existir propio) y la vivencia del tiempo escatológico (como precursor de lo que significará después Sein zum Tode).

¿Cómo se mantiene la fe en la experiencia del cristianismo primitivo? ${ }^{17}$ La economía del cristianismo apunta a un tiempo, el tiempo de la salvación que es el tiempo que los cristianos, de hecho, están viviendo ${ }^{18}$. En la primera venida de Jesús ha acontecido pleroma tou chronou, la plenitud del tiempo que se produce cuando Dios envía a su hijo nacido de una mujer, nacido bajo la ley. Se inaugura así el tiempo de una nueva historia marcada por la oportunidad definitiva del pacto de Dios con los hombres que llega a su cénit en la cruz y que espera su culminación en la segunda venida que acontecerá en un futuro que se proclama ya próximo. La existencia acontece en este mientras tanto de un futuro que adviene. El tiempo presente ha llegado a su fin. Se abre ahora un nuevo aion constituido por la esperanza que proyecta lo que ha de venir hacia atrás, hacia lo ya sido y hacia el estar siendo.

El tiempo cristiano es, por tanto, el tiempo que queda hasta la venida del Señor, hasta "el día de Cristo" (Flp 1, 10). La parousia acontecerá "como ladrón en la noche"19. Por ello, el tiempo del creyente ha quedado abreviado (1 Cor 7, 29-32), y cuanto más es consciente de esta temporalidad comprimida (zusammengedrängte) más se incrementa su tribulación (Bedrägnis) ante una salvación que promete ser definitiva en un mundo que aún no transparenta esa verdad. El mundo pasa (paragei to schema tou cosmou); la forma de lo mundano nunca permanece. Se trata de vivir de otra

${ }^{17}$ Para la exposición de la influencia de Pablo en Heidegger tomamos algunas de las reflexiones ya publicadas en Chillón: "Ser en el mundo sin ser del mundo. Serenidad y direcciones del cuidado en Heidegger" y Serenidad. Heidegger para un tiempo postfilosófico.

${ }^{18}$ Son muy sugerentes los trabajos de Casale, "La interpretación fenomenológica de Heidegger de la escatología paulina”, Teología y vida, vol. XLIX, 2008, pp. 399-429; De Lara, "Heidegger y el cristianismo de San Pablo y San Agustín”, Eidos, 7, 2007, pp. 28-46; Berciano, "Esperando su venida. Comentarios heideggerianos de escatología paulina", $\mathrm{Na}$ turaleza y gracia, 2-3, 2000, pp. 429-459.

${ }^{19}$ La condición escatológica queda descrita en 1 Tes 5, 4-5 mediante antítesis como día y noche, luz y tinieblas que vuelve a aparecer en Rom 13, 12 con la contraposición entre lo pecaminoso del mundo y lo divino. 
manera, libres de preocupaciones (amerimnous) pero para ello el cristiano debe ser consciente del kairós en el que vive ${ }^{20}$. ¿Cuál es el aspecto fundamental que determina el grado de compromiso del cristiano con esa temporalidad del advenir definitivo que transparenta su esperanza? Sin duda el cuidado para con el mundo circundante. Leyendo 1 Cor 7,32 , se puede identificar el cuidado, en términos heideggerianos, con la actitud de preocupación que todo cristiano ha de tener por las cosas del Señor y por las cosas del mundo. No sería una manera auténtica de existir la despreocupación por el mundo para ocuparse de las cosas de Dios, sino más bien al contrario, ocuparse de la esperanza debe redundar en algún tipo de compromiso con el mundo que sirva de testimonio ${ }^{21}$. Y esto porque algunos de los que se sienten vinculados por la inminente venida de la parousia pasan el día perdidos y holgazaneando al no haber entendido que el kairos no tiene que ver con la cronología ${ }^{22}$. Su despreocupación por las contingencias de la vida les lleva al extremo de "hablar sin decir nada convirtiéndose en una carga onerosa para los demás" (1Tes 4,11). Quienes saben cómo esperar están en la luz; quienes haciéndolo se olvidan del mundo o se pierden en el mundo (viviendo como si Dios no existiera o como quienes viven sin esperanza) andan en las tinieblas (Gal 5, 4).

${ }^{20}$ El kairós cristiano es asumido por la fenomenología como el instante del fenómeno originario de la temporalidad originaria. Un instante que Aristóteles ya intuyó en el libro VI de Ética a Nicómaco. El instante (Augenblick) es "el presente que se mantiene en el estar resuelto y surge de él”. Heidegger, M., Los problemas fundamentales de la fenomenología, Madrid, Trotta, 2000, p. 345. Para una mayor profundización, cfr. Haar, M., "Le moment (kairós), l'instant (Augenblick) et le temps du monde (Weltzeit) en Heidegger 1919-1929", en Courtine, J. F., De l'herméneutique de la facticité à la métaphysique du Dasein, Paris, Vrin, 1996, pp. 67-90.

${ }^{21}$ Se espera que los fieles no se aparten del mundo condenado y sin remedio (1 Cor 5, 9-10) sino que resplandezcan en medio de ese mundo (Flp 2, 15). La propia experiencia de Pablo tiene que ver con el olvido de lo que ha dejado atrás y la salida en tensión a lo que queda por delante (Flp 3,13). Como explicará después en 1 Cor 9, 24 se trata de correr hasta la meta, una meta que está más allá de la promesa salvífica vana del presente. Los hijos de la luz, aunque incorporados a lo celeste, pisan firme en la tierra manteniéndose en expectativa al Señor que ha de venir (Flp 3, 20).

${ }^{22}$ Agamben, G., El tiempo que resta, Madrid, Trotta, 2006, ha visto genialmente esta idea para tratar de vincular la concepción paulina del tiempo con el concepto benjaminiano de tiempo mesiánico que "no es, sin embargo, otro tiempo, algo así como un tiempo suplementario que se añade al tiempo cronológico; es, por así decirlo, un tiempo dentro del tiempo - no ulterior, sino interior- que mide mi desfase respecto a él.” p. 72. Es la diferencia entre las dos dimensiones del tiempo operativo interno (kairós) y el tiempo cronológico o imagen del tiempo. 
Y entonces ¿cómo ha de vivirse la esperanza de la parousia en el ya de la existencia? Viviendo plenamente en el mundo, viviendo las cosas del mundo como si no ${ }^{23}$ (1Cor 7, 30). Vivir como si no es vivir cara al futuro donde toda plenitud mundana resulta vana, donde todo hartazgo de placer deviene vaciedad, donde toda ganancia humana es considerada pérdida ${ }^{24}$. En ese sentido, el cristiano vive ya no en el tiempo sino el tiempo mismo, sostiene Heidegger. La temporalidad proviene de esta forma de entender la peculiaridad de la existencia cristiana que no queda apegada a las cosas. El abrigo que la realidad mundana da a la intemperie de la existencia es solo provisional y, como todo lo provisional, no solo es contingente por definición, sino incapaz de proyectar algún tipo salvación en términos de sentido a lo precario del hombre. El cristiano vive en el todavía del tiempo que falta para la venida definitiva. Vivir en las cosas, permitir que la defluxio se convierta en una especie de doble naturaleza, solo sirve para ocultar los síntomas de la angustia pero no para resolver de una vez por todas el foco de la misma. De esto vive la tentación: de eliminar en apariencia lo insoportable del vacío humano para que las cosas sean la única solución a una existencia connaturalmente angustiosa. Vivir en el tiempo es vivir cegado para la temporalidad.

Pues bien, su estructura, la estructura de la esperanza, según Heidegger, constituye un anticipo en toda regla de esta temporalidad de la facticidad. Una estructura que de alguna manera pone entre paréntesis el mundo en lo que podría denominarse una especie de reducción fenomenológico-existencial de las cosas hacia el interior del hombre cuya esencia se resuelve en esa tensión escatológica que tiene que ser mientras resiste a la irrefrenable tentación del mundo.

Vayamos a nuestra interpretación fenomenológica de san Agustín y de sus Confesiones para explicitar, después, cómo pudo servir esa vivencia religiosa para la determinación de lo que significa pensar. La cuestión decisiva

23 "Como si expresa un complejo objetual y sugiere la idea de que el cristiano debe desactivar esas referencias al mundo circundante. Este hos significa positivamente un nuevo destino que se añade. El me concierne al complejo ejecutivo de la vida cristiana. La vida cristiana no es rectilínea sino quebrada”. Heidegger, M., Introducción a la fenomenología de la religión, Madrid, Siruela, 2005, p. 149.

${ }^{24}$ En el último trabajo de Sloterdijk, se vincula este $u t$ non paulino con el inicio de toda una tradición gnóstica cuya tesis fundamental es la incompatibilidad entre el alma creyente y el mundo. Se trata de un anticosmismo gnóstico (por cierto que ya Hans Jonas anticipó que la analítica existencial del Heidegger de Ser y Tiempo parecía contener las enseñanzas básicas de la gnosis y su extrañeza frente al mundo) que hace de la gnosis "una filosofía del como si no". Sloterdijk, P., La herencia del Dios perdido, Madrid, Siruela, 2020, p. 65. 
es esta: la revelación de Dios en la historia incardina la experiencia de la fe en el tiempo, en la vivencia, en el kairós. Todo significado queda retocado por el sentido existencial que imprime la fe que, para el obispo de Hipona, tiene que ver con un acto interior de decisión y de entrega. Agustín es el primero en asumir la realidad del interior: la experiencia interna de la existencia de Dios. Pero esa experiencia interna es constatable una vez que uno mismo se ha puesto en cuestión: questio mibi factus sum. Confesarse ante una trascendencia que todo lo sabe solo puede tener sentido desde esta nueva necesidad de saberse ${ }^{25}$ : la inmanencia busca abrigo en la trascendencia. El acceso al interior ${ }^{26}$, el volverse problemático para sí mismo, es el resultado de la pregunta que ya no encuentra satisfacción en la connatural versión exterior de lo humano ${ }^{27}$. Muy al contrario de las respuestas del mundo, es en el interior donde habitat veritas y donde se puede escuchar a Dios. Si hay teología, entonces, solo puede ser desde una filosofía de la interioridad ${ }^{28}$. La inmanencia encuentra su redención en la trascendencia, lo acabamos de decir. No hay otro camino al afuera siempre mayúsculo que el de la interioridad. A la totalidad por la finitud; a la salvación por la precariedad; a la gracia por la debilidad. Este nivel óntico del hecho religioso, en el que vamos a insistir enseguida, provee al I Heidegger, ya lo hemos dicho, de las indicaciones formales de lo que en Ser y Tiempo será la analítica existencial y por tanto del material de trabajo para el nivel ontológico que se busca. Nuestra propuesta es que estos dos niveles, exactamente en esta misma relación entre lo óntico y lo ontológico, se mantienen también en la vinculación

25 “Cognoscam te, cognitor meus, cognoscam sicut et cognitus sum”. Conf. X. I, 1.

${ }^{26}$ En el Prólogo a Contra Academicos, Agustín escribe a Romaniano que no cesa rogar a Dios para "que te vuelva a ti mismo (...) y tu ánimo, impaciente por respirar, salga, por fin, a la atmósfera de la verdadera libertad". 1.1.1. Poco más adelante explicará que, vivir la verdadera vida significa vivir según la razón. ¿Dónde radica la verdadera sabiduría? En apartar de su mente todos los lazos corporales y concentrarse en sí mismo: "cum ab omnibus involucris corporis mentem quantum potest evolvit et seipsum in semetipsum colligit". 1. 8. 23. El premio de la confesión —escribe Sloterdijk- es que quien dice la verdad entra en la verdad instaurando así el drama lógico de la intimidad. "Después de la conversión a la religión verdadera, la verdad ya no puede valer meramente como una propiedad de proposiciones y discursos; por así decirlo, la verdad tiene que conformar el en en el que todo discurso y vida queden sumergidos", p. 95.

${ }^{27}$ Confesar a Dios forma parte del mismo movimiento de humillación, de abajamiento: "nihil est aliud confiteri tibi quam displiceri mihi". Conf. X, 2, 2.

${ }^{28}$ La importancia de san Agustín en Heidegger puede evidenciarse también a partir de la decisiva influencia que sus trabajos tuvieron en discípulos de la talla de Hanna Arendt y su tesis doctoral titulada Der Liebesbegriff bei Agustin de 1929, y en Hans Jonas con su trabajo de 1930, Agustin und das paulinische Freiheitsproblem. 
entre el contenido de la vivencia espiritual e interior y la dimensión meditativa del pensar que, como veremos, abre al hombre a la dimensión de lo sagrado.

Un ejemplo evidente de cómo se trabaja con estas dos dimensiones en los primeros cursos de Heidegger, podemos verlo en la importancia capital de lo que significa fenomenológicamente el hecho de preguntar. Se puede ver en las Confesiones algún antecedente preclaro de la fenomenología del preguntar con la que se abren las páginas de Ser y Tiempo. Para Agustín, el acceso al interior se genera en la necesidad de preguntar que, ante todo y sobre todo, implica buscar. Un buscar que, gracias a la participación directa de la memoria (que nos permite recordar y de algún modo ya saber lo que buscamos) puede entenderse como un ya-haber-encontrado ${ }^{29}$. Sólo buscamos lo que sabemos ya, o lo que en algún momento hemos sabido, pero hemos olvidado ${ }^{30}$. De ahí el influjo capital de la memoria, con todas las resonancias neoplatónicas al respecto.

Pues bien, si se profundiza en esa comprensión primera del preguntar, se descubrirá la faz meditativa del hecho mismo de la pregunta en la medida en que la pregunta no es la contrapartida de la intención de alcanzar seguridad, ni del deseo de saber que, desde Aristóteles, parecía mover a todos los hombres, sino la "búsqueda que ama el abismo" ${ }^{31}$. Así, por medio de la pregunta, por medio de esta expresión de la renuncia a lo dado, por medio de esta manera de ser buscador (que Heidegger asemeja a ser guardián, cuidador), el hombre descubre la indigencia del abandono del ser en la que reside, quién lo iba a decir, la verdad misma del ser. Hacerse cargo de la pregunta, en cuanto meditación, exige tomar en cuenta la repercusión que esa indigencia tiene en aquel que busca la verdad. Preguntar, en nuestra

${ }^{29}$ Según el trabajo de Jonas, la relación rememorativa y no instrumental respecto de Dios permite eliminar esa relación de desvaloración que, según se deduce de los textos de Agustín, el deseo instaura con el mundo. Es como si el deseo, por sí solo, sin la memoria que hace rememorar a la criatura su provenir de Dios, estableciera una especie de relación impropia con el mundo inestable insistiendo así en su falta de significado. Cfr. Savarino, L., "La influencia de la interpretación del cristianismo. Arendt y Jonas" en Heidegger y el cristianismo, Buenos Aires, Prometeo, 2017, pp. 177-196.

${ }^{30}$ La búsqueda sólo puede ser "per recordationem (...) oblitumque me ese adhuc teneam". Conf. X, 20, 29.

${ }^{31}$ Cfr. Heidegger, M., Beiträge zur Philosophie, p. 12. El preguntar suscita de inmediato la sospecha del vacío aferrarse a lo inseguro, indeciso, indecidible. Se excluye como un retirarse del saber a la quieta meditación. Cfr. p. 10. Preguntar es meditar en cuanto poner en cuestión el sentido, en cuanto pregunta por la verdad del ser, en cuanto salto hacia su esencia. Cfr. p. 43. 
opinión, puede comprenderse como la indicación formal de lo que quiere significar, en el II Heidegger, el hecho mismo del pensar en cuanto meditar. Aquello que es objeto de la pregunta nunca termina de darse del todo, de la misma manera que la meditación es una tarea siempre inconclusa.

Toda meditación acaba siendo una automeditación, un hacerse cargo de nuestra propia experiencia interior, de la misma manera que en toda pregunta es uno mismo quien también se pone en cuestión. Pues bien, esta experiencia interior es la que —según san Agustín- aspira a la felicidad, a una vita beata que no tiene componente sensible, que no es un mero estado material, y que siempre está pendiente de ser conseguida por todos los hombres. Y de entre todas las búsquedas, solo colma esa ansia de gozo verdadero el gozo de Dios. Es fácil, entonces ver que, si en el interior está la verdad y ese interior busca una plenitud auténtica, termine diciendo que "veritas est vita beata".

Creemos que es muy importante introducir aquí el adjetivo referido a la autenticidad (con una carga moral de la que Heidegger se libera para hacer posible su trabajo ontológico haciendo que la Eigentlichkeit se refiera más bien a la propiedad) porque, según Agustín, la mayoría de los hombres colman su búsqueda entregados a otros asuntos más bajos, menos trascendentes ("fortius occupantur in aliis") con la constatación de que todo esto externo en lo que cifran su felicidad es, además, costoso y fatigoso ${ }^{32}$. No sucede así con la verdad que está en el interior. Toda ocupación de la vida habitual es esencialmente caída que termina confundiendo y alterando los términos del amor y de la verdad: ya no es que los hombres amen la verdad, sino que quieren "que lo que aman sea la verdad" 33 . Y todo ello por el miedo a la desnudez del vacío, a la cobardía ante las imposiciones de la moda o de la tradición... ¿Dónde radicaría si no ese esfuerzo ímprobo por dar con una verdad no verdadera en las cosas, en el mundo, cerrándose a la auténtica felicidad que radica en la vuelta a sí?

32 "La causa principal del error humano es que el hombre no se conoce a sí mismo. Para conocerse es necesario separarse de la vida de los sentidos y replegarse en sí y vivir en contacto con la voz de la razón”. De Ordine, 1. 1.3. Y un poco más adelante insiste: "Quisquis ea sola novit, quae corporis sensus attingit, non solum cum Deo esse non mihi videtur sed ne secum quidem". De Ordine 2. 2. 5.

${ }^{33}$ Esta forma de trastocar los contenidos de la verdad y el nivel afectivo que les corresponde provoca esa cerrazón a oír lo que de verdad importa y los convierte en oyentes de lo que les importa. El problema de la inautenticidad es que ni siquiera considera importante preguntarse por el cómo de su pregunta, esto es, por la actitud que el hombre posee para enmendarse en función de la verdad. 
Los hombres están asediados por el miedo a ser descubiertos por la verdad; por la vergüenza que sucede cuando se levanta el telón de la mentira y la nuda realidad queda a la intemperie; por la reiteración de aquella primera experiencia de Adán y Eva que tienen que cubrirse por haber sido descubiertos. Este es, entonces, el sentido de la confesión, del estar del yo ante sí mismo, del pasar a primer plano la gran cuestión sobre quién sea este que soy yo: el acceso al otro hombre que deja en evidencia al hombre exterior, la oportunidad para el paso atrás de las urgencias de la vida, para el retiro de las certezas mundanas, para entreparentesizar las demandas del mundo y encontrarse consigo mismo.

Por medio de la confesión, el yo se pone ante sí para descubrirse afectado por las tentationes (ya sean las que tienen que ver con la concupiscentia carnis, con la concupiscentia oculorum o con la concupiscentia saeculi) ${ }^{34}$. Y esto es ahora lo decisivo: solo puede hablar de tentaciones el que se sitúa a distancia del común discurrir de la vida siempre empujada al mundo. Por ello, la oportunidad de una confesión, tachada de absurda por incomprensible para el modo habitual de ser hombre, solo puede ser comprendida en su sentido completo por el hombre preocupado por su autenticidad. La llamada de la fe es, antes que nada, una llamada a la vida interior, al conocimiento de sí, al noli foras ire. La inquietud constante por esa felicidad, que nunca lo es del todo en las coordenadas de lo inmanente, acontece con una Befindlichkeit de serenidad y de paz interior que contraviene la aparente quietud que dan las cosas en una seguridad que no hace más que inquietar al hombre que nunca se encuentra saciado con ellas.

Llevamos en nosotros mismos el sello de la indigencia; nuestra propia carne es su mejor exponente. Somos constitutivamente menesterosos. Nuestra cotidianidad es un periplo de servidumbres y de necesidades: desde la más básicas, a las afecciones del dolor que reclaman ser paliadas. Todas ellas apremian y todas ellas forman parte de la facticidad del existir ${ }^{35}$. En el

${ }^{34}$ Pueden parecer igual todas las tentaciones, pero no lo son. Heidegger se dedica desde el parágrafo 13 de "Agustín y el neoplatonismo" a exponer las diferencias notables entre ellas lo que le permite una exposición fenomenológica de las mismas. Tiene especial importancia la ambitio saeculi, la que tiene que ver con el modo en el que ser humano se da importancia, la manera en la que el hombre se sitúa en una verdadera posición de superioridad y entendiendo, entonces, la convivencia en el mundo compartido como una expresión de sus imposiciones a los otros. En este caso, el curare del mundo en modo tentación termina construyendo — sostiene Agustín - una misera vita movida por una foeda iactantia.

35 "La experiencia de Dios no radica, por el contrario, en el sentido de Agustín, en un acto aislado o en un momento determinado de un acto tal, sino en un nexo de experiencia de la facticidad histórica de la propia vida. Esto es lo auténticamente originario”. Heidegger, “Agustín y el neoplatonismo" en Estudios sobre mística medieval, p. 150. 
placer de la plenitud que se experimenta en la recompensa de la necesidad sentida reside la raíz de toda concupiscentia. Es como si el mundo pudiera curar nuestras heridas, rellenar nuestras carencias, reparar nuestras roturas. Y entonces, al trasponer esa economía mundana a todas las demás dimensiones del hombre, o se sorprende al mundo en su silencio ante lo que de verdad nos preocupa esencialmente, o el hombre termina convenciéndose de que todos aquellos cuestionamientos tan profundos de nada sirven. La clave es la siguiente: la experiencia del encuentro con la verdad, que es la experiencia de la reducción a sí, queda blindada para cualquier intelección exclusivamente teórica incorporando los estados de ánimo ${ }^{36}$ a la comprensión de lo que signifique ser para este ente que somos cada uno de nosotros. Por ello, la señal inequívoca de que uno ha dado con la verdad es el gozo pleno, el deleite verdadero, la misma vida: "cum inhaesero tibi ex omni me (...) et viva erit vita mea" ${ }^{37}$. Pero, probablemente, esta maduración siempre llega tarde. La biografía de Agustín es un claro exponente de cuánto hay que perderse para luego encontrarse. Por eso, "sero te amavi, Domine". Siempre es tarde, pero siempre se está a tiempo. Porque la tendencia natural a la dispersión, a abandonarse al mundo ${ }^{38}$, a disfrutar de sus placeres y a huir de sus peligros, neutraliza cualquier intento de pensar.

Cara al mundo no cabe otra cosa que la disipación en lo mundano y el desmoronamiento de la existencia. La constante versión hacia afuera, la entrega sin par a las demandas del mundo, es una expresión evidente de egoísmo. Y esto es porque, a pesar de las múltiples diferencias entre la tipología agustiniana de la concupiscentia, todas ellas son modos del vivir tentado, así que entre ellas debe existir un denominador común. ¿Qué tiene que ver, entonces, la inclinación a los deseos de la carne, con la curiosidad y el querer saber solo por tener sabido (que diría Heidegger) o el ansia de reconocimiento y de poder? Que todas ellas son maneras de dejar a la naturaleza humana campar a sus anchas, sin control, sin medida. Que todas ellas son modos de dejarse caer, heideggerianamente hablando ${ }^{39}$.

36 "Non intratur in veritatem nisi per charitatem", había escrito Agustín.

${ }^{37}$ Conf. X, 28, 39.

${ }^{38} \mathrm{El}$ hombre de espaldas a Dios acaba siendo un deforme que "se lanza sobre las cosas hermosas que tú creaste”. Conf. X, 27, 38. Es interesante observar cómo toda la tradición paulina-agustiniana-luterana expresa el modo de vida mundana con palabras que connotan caída, descenso, abandono... "Con el peso de mis miserias vuelvo a caer en estas cosas terrenas y a ser reabsorbido por las cosas" Conf. X, 40, 65.

${ }^{39}$ De toda la tipología de las tentaciones, la que toca más la médula de lo humano es la que tiene que ver con el tomarse uno como importante. Este modo de gustarse a sí mismo acontece o bien porque se toman por buenas las cosas que no lo son, o porque se consideran 
Efectivamente, bajo las especulaciones agustinianas no solo hay una experiencia vital real, que sigue aconteciéndonos y en la que fácilmente podemos vernos identificados, sino un aparente pesimismo antropológico: el hombre, por sus propias fuerzas, no puede acertar a vivir auténticamente. La experiencia humana, sin Dios, acaba siendo una experiencia inhumana. Pero esto solo lo sabe quien gira la mirada. Aquella transformadora experiencia platónica del prisionero de la caverna que cambia la dirección de su mirada para inaugurar otro modo de pensar, esto es, otro modo de vivir, se reedita ahora en la llamada a un cierto tipo de conversión como la que supone pasar de fuera a adentro, del hombre exterior al hombre interior. No es solo entonces que Agustín posea una antropología pesimista que necesite acudir a la gracia divina para sostener la existencia constitutivamente abismada del hombre, sino que esta constatación de la tendencia natural del hombre a hacerse a sí mismo de espaldas a Dios posee la inamovible certeza de cuán ciego es nuestro destino sin la luz que al revelársenos, nos revela. La carga de la existencia empieza a mostrarse onerosa en el momento en el que hombre cuenta solo con sus posibilidades ${ }^{40}$.

Podemos entender, desde nuestra interpretación fenomenológica de las Confesiones, cómo en Agustín se exponen esas dos dimensiones de la caída de las que se hará cargo la analítica existencial heideggeriana: la que corresponde al arrojamiento del Dasein a la existencia, a su "ser echado al mundo" que diría Pöggeler, y al modo de redundar en esa cadencia propio de la existencia inauténtica. Y es que las Confesiones habían insistido tanto en la imborrable mancha que determina el recorrido de lo humano, como en la gracia que, asumiendo la debilidad de la naturaleza, la lleva a su perfección ${ }^{41}$. ¿No puede ser entendida la gracia desde Heidegger, en cuanto incitación a lo que salva, como una indicación formal de lo que se quiere decir con el pensar en cuanto apertura al misterio? (Offenheit für das Geheimnis). La cerrazón a la gracia podría, entonces, ser explicada, heideggerianamente, como una huida del hombre ante sí mismo. Ese bloqueo de lo trascendente, en nuestra opinión, obtiene los mismos rendimientos

como propios los bienes que son de otros, o si los consideran divinos los atribuyen a sus propios méritos, sostiene Agustín. Esto constituye, ahora en palabras de Heidegger, "la posibilidad de la caída abismática y del genuino perderse uno a sí mismo”. Heidegger, M., “Agustín y el neoplatonismo", p. 97.

40 "Como al que tú llenas lo elevas, me soy carga a mí mismo, porque no estoy lleno de ti”. Conf. X, 28, 39.

41 "Por la dulzura de la gracia divina (...) el hombre termina siendo consciente de su debilidad". Conf. X, 3. 4. 
para el hombre que la falta de pensamiento que conmina al ser humano a vaciarse en el mundo, a abandonarse en las promesas de la técnica, a razonar desde el único patrón de racionalidad, a, en definitiva, insistir más en su constitución cadente. Desde aquí la vida humana cae, se abandona a sí misma, se debilita, se dispersa. Que las Confesiones son un caladero para el trabajo hermenéutico fenomenológico de Heidegger es más que evidente. Que, efectivamente, el dramatismo del alejamiento de Dios y sus consecuencias existenciales y morales no están en Heidegger, no tiene discusión. Sin embargo, nuestra investigación quiere encontrar en las Confesiones de Agustín esas marcas en el camino, esos hitos sobre los que se asienta el giro heideggeriano y su comprensión del Dasein, del ser y del pensar.

La redención comienza siempre en Dios, pero de nada sirve si el hombre no se convierte. La experiencia fenomenológica, ya en Husserl, había asumido este cambio existencial parecido a una conversión religiosa ${ }^{42}$. La tentación, el enemigo de nuestra propia felicidad ${ }^{43}$, está en el mundo y en la mundanización de todo lo humano hasta conseguir des-autentificarlo al proyectar sus lógicas a lo propio del hombre. La tentación conecta con la naturaleza humana en sus pasiones, en sus ínsitas inclinaciones y en sus carencias. Pero esa conexión no sólo es más débil de lo que aparenta ${ }^{44}$, sino que acaba construyendo una concepción de hombre que desatiende a su interior, y por tanto a aquella dimensión donde radica la verdad de su ser creatura, el sentido de su vida y la fortaleza para ese otro modo de vida que acontece, y esto es claro en Agustín, desde el otro modo de pensar. Desde aquí creo que es fácil entender lo que parece querer decir Heidegger: cómo ese otro pensar es el modo de continentia ante la tentatio. Continentia que no significa propiamente moderación, sino conciencia de lo que falta. Este cambio semántico, evidentemente, obedece a esa transfiguración ontológica que Heidegger lleva a cabo de las categorías con las que Agustín comprende la existencia cristiana marcada por el pecado. Pues bien, la experiencia de la continentia, ya sin la mácula original, sigue siendo una experiencia

42 "La actitud total fenomenológica y la epojé pertinente está esencialmente llamada a obrar, en primer lugar, una transformación personal que tendría que ser comparada con una conversión religiosa, la que más allá de eso entraña en sí el significado de la más grande transformación existencial que se ha propuesto al ser humano como ser humano”. Husserl, La crisis de las ciencias europeas, p. 144.

43 "Adversarius verae beatitudinis nostrae". Conf. X, 36, 59.

${ }^{44}$ Por eso, el de Hipona sabe que la justificación tipo "el ser humano es así" o similar, no es más que una excusa que, en realidad, desconoce lo que sea la naturaleza del hombre. Cfr. Conf. X, 37, 61. 
ubicua y permanente en el ser humano: siempre falta algo. La marca de nuestra facticidad es precisamente la de ser una existencia completamente incompleta. Agustín ya había hablado de la carga del existir consistente en tener que hacerse cargo de las molestias et difficultates, no para asumirlas con la resignación de un mandato inapelable, sino para integrarlas como ingredientes constitutivos del bregar humano en el mundo. Existir es carga porque es conflicto ${ }^{45}$. El contenido de esta carga no puede amarse, es imposible. Lo que sí puede amarse, explica san Agustín, es el cómo enfrentarse a eso que constituye una carga. Y ese cómo es el que nos pone sobre la pista de la vida real, de la vida fáctica que tanto llamó la atención del joven Heidegger. Tales actitudes, tales estados anímicos, constituyen la experiencia vital que es siempre la experiencia de la vulnerabilidad, de la finitud, de la pequeñez. Por eso la vida humana es esencialmente tentación ${ }^{46}$, porque exige una maduración especial el aceptar la herida de lo humano comparado con la satisfacción que, aun costosa y parcial, otorga el mundo.

Fenomenológico-hermenéuticamente se puede decir que la reflexión sobre la tentación es ya un modo de tomarla en cuenta, de tener conciencia de ella y, por tanto, de preguntarse por ella, de separarse del común y habitual modo de darse el mundo al hombre. Agustín ya había explicado que solo en la tentación el hombre sabe quién es. Ahí, donde la vida humana se encuentra en el punto álgido de su ruina, donde los asientos del sentido no encuentran firme, el ser humano termina sabiéndose ${ }^{47}$. Para lo cual, la experiencia del autoconocimiento deja de ser una experiencia teórica expuesta en la lógica epistémica habitual (evaluada en función de su objetividad), para pasar a ser una experiencia emocional en la que uno se descubre no en el "qué" de su vida, sino en el "cómo" del propio vivir que no permite distancia para ser tratado con neutralidad, y mucho menos perspectiva para evitar el prejuicio.

${ }^{45}$ Conflicto en forma de contradicción que se hace patente en el modo como el hombre, sin la luz divina, no entiende que "las demás cosas de esta vida tanto menos se han de llorar cuanto más se las llora, y tanto más se han de llorar cuanto menos se las llora". Conf. X. I, 1. "Oneri mihi sum" Conf. X, 28, 39.

${ }^{46}$ De hecho, ¿hay algún lugar en la vida humana en el que no exista la tentación? ¿No es la tentación sin interrupción la vida del hombre sobre la tierra? Cfr. Conf. X, 28, 39.

${ }^{47} \mathrm{Y}$ es que, en la caída, aparece para el ser humano la oportunidad o bien de dejarse caer en una insistencia en lo cadente que pasa desapercibida, o la posibilidad de acceder así "al ser de la vida más propia”. Heidegger, “Agustín y el neoplatonismo”, p. 101. 


\section{La experiencia de la fe en Agustín como indicador formal del pensar}

En las cartas paulinas, Heidegger atiende al modo de vida que no se deja captar por la mera intención teorética; en Agustín asistimos a la reintroducción de las categorías de la metafísica clásica dentro del universo espiritual cristiano-paulino $^{48}$. En nuestra opinión, aquí, en Agustín, Heidegger observa lo que sucede con un pensamiento que trastoca la lógica tradicional del quehacer metafísico hacia el reconocimiento del fundamento que nos hace ser y que no se dejar asir ni captar con esos rudimentos del pensar habituales. De modo que el trayecto que acabamos de señalar en el punto anterior desde Pablo a Agustín representa el tránsito que va de la recuperación de la originalidad de la experiencia religiosa (sin la contaminación conceptualizadora de la escolástica) hasta la comprensión del camino de la fe como un proceso de conversión que ya no aspira a la originalidad e ingenuidad de lo vivido, sino al uso (podríamos decir, deconstructivo) de las categorías metafísicas. La fe es una experiencia de totalidad; toda la existencia queda tocada, redefinida y transformada por ella. Así pues, esta experiencia espiritual es una experiencia existencial que consiste en un abandono "de", que sólo puede darse si, en el mismo momento, se da un abandono "en" ${ }^{49}$. El régimen preposicional explicita la experiencia religiosa que es, como en Eckhart y en Teresa de Jesús ${ }^{50}$, una experiencia de desasimiento de todo, una vez que el hombre se pone "en" manos de Dios. La diferencia semántica entre la versión transitiva del verbo abandonar (dejar algo) y la intransitiva (dejarse) advierte de esta riqueza experiencial del doble movimiento que interesa al pensar heideggeriano atendiendo a la transformación que su hermenéutica fenomenológica opera sobre lo trascendente de la mística: del absolutamente Otro en el que dejarse, al ser que en su fundamento invita al

${ }^{48}$ Cfr. Savarino, p. 33.

${ }^{49} \mathrm{El}$ reconocimiento de la pobreza y de la indigencia personal lleva aparejado una cierta displicencia respecto de sí mismo, un desagrado de uno mismo necesario para la búsqueda de la misericordia divina. Conf. X, 38. 63.

${ }^{50}$ Estar vacío de todas las cosas creadas, explica Eckhart, Sermón 86, es estar lleno de Dios, y estar lleno de cosas creadas es estar vacío de Dios, o el ampliamente conocido poema de Teresa de Jesús: "Nada te turbe, nada te espante, quien a Dios tiene nada le falta", son una buena muestra de esta experiencia del desasimiento, de lo que Heidegger pudo entender con el término Gelassenheit. En nuestra opinión, aquel negarse a sí mismo de la tradición mística se entiende mejor desde esta interpretación fenomenológica. Sobreponerse a lo real, desconectar la corriente cotidiana de la impresión de la vida, neutralizar el momento impulsivo de volcado al mundo, son contenidos que están latiendo en ese otro pensar y en las actitudes a él vinculadas de las que habla Heidegger, por ejemplo, esta de la serenidad. 
ser humano a estar en su sintonía y, de esta manera, descubrirse a sí mismo justo en el momento en el que va dejando de lado la voluntad que le ata a las cosas.

Esta es, en suma, la tesis de nuestra investigación: el camino que va del tratamiento de lo religioso como indicador formal de lo que signifique ser en el mundo (con esa relativa influencia del contexto cristiano en sus primeros trabajos) al descubrimiento de los conceptos núcleo de la experiencia creyente como indicadores formales de la experiencia del otro pensar. Sustitúyase la experiencia de la fe por la experiencia de este otro pensar, y se entenderá mejor lo que quiso exponer el Heidegger de la Kehre ${ }^{51}$.

En definitiva, la búsqueda de la interioridad en Agustín pudo poner al de Messkirch sobre la pista de un cierto método del pensar que va de fuera a adentro, de las cosas al sí mismo. Porque, en realidad, la concepción de la filosofía de Agustín, como buen heredero de la tradición filosófica de Platón, termina siendo una forma de vida. Quizá sea esto lo que llama la atención de Heidegger: el acceso al interior no es una opción más entre otras, sino el modo genuino de dar con la verdad. Esta otra manera de pensar, que es otra manera de vivir (en la que el hombre encontrándose consigo alcanza a Dios) es la que parece seducir las primeras reflexiones de Heidegger (al menos para ofrecerle el vergel en el que hallar enjundiosas nociones explicativas de lo que sea el existir) y, como venimos diciendo, las relativas al pensar. Experiencia religiosa frente a teología, mística contra escolástica o vida versus sistema explicitan lo que significa la superación de la perspectiva teórica y su estructura subyacente de sujeto-objeto. Con Pablo y Agustín, de la mano de Lutero y Eckhart, el sentido de la experiencia religiosa cristiana consiste, más que nada, en dejar a Dios ser Dios ${ }^{52}$ dejando también ser a las

${ }^{51}$ Sostiene Gadamer que, en uno de los intercambios epistolares entre Löwith y Heidegger, este último, después de insistir en su identidad como teólogo cristiano, declaró que la verdadera tarea de la teología era "encontrar la palabra que es capaz de llamar a la fe y de hacer permanecer en la fe". A esta tarea, prosigue Gadamer, se le puede denominar la tarea del pensar. Gadamer, H. G., "La dimensión religiosa" en Los caminos de Heidegger, Barcelona, Herder, 2017, p. 158. Hay que tener claro que la calificación de Löwith es de los años 20 y que, efectivamente, Gadamer es especialmente restrictivo en la interpretación de la esta designación. De hecho, ya el propio autor escribía su opinión al respecto unas páginas antes: "Heidegger puso en claro de manera inequívoca que la pregunta por el ser, cuyo nuevo planteamiento asumió más propiamente, no se debía entender como la pregunta por Dios". Gadamer, p. 151.

${ }^{52}$ Savarino, p. 19. El mismo autor, páginas antes, aclara cómo el nacimiento de la experiencia religiosa es un acontecimiento que se abre a tres dimensiones constitutivas de sentido: el sentido de contenido (Gehaltsinn) que puede ser reconstruido con los instrumentos de la crítica histórica y de la exégesis bíblica; un sentido de referencia (Bezugsinn) que debe ser 
cosas lo que son, sin la imposición humanista que pretende tomar el lugar del absoluto, y que, al final, busca ser como Dios. El pensar meditativo, en este tiempo de la técnica, toma las notas de la contemplación ascética y todas sus consecuencias al respecto: el desasimiento, el desapego y una cierta dosis de ingenuidad que permite al pensar más que hacer, dejar ser. Ya en Tiempo y ser, Heidegger había sostenido que el significado más profundo del ser es el dejar ${ }^{53}$ como invalidando cualquier intento de vincular el ser al modo de ser del ente siempre susceptible de caer bajo la objetivación del conocimiento o bajo la objetualización de la voluntad. Y con toda esa carga y, a partir también de la experiencia mística de oriente, el pensar meditativo heideggeriano retoma la perspectiva de aquella pobreza espiritual del no desear nada, del no saber nada (en el sentido de la engreída sabiduría mundana), del no tener nada. De alguna manera, el Agustín de Heidegger, como su Pablo, su Maestro Eckhart... son traídos para mostrar un conocer de otro modo, un saber desinteresado que corre desnudo hacia su fundamento, un modo paradigmático de vivir sin la esclavitud de la voluntad, un descubrimiento de la plenitud en el vacío de la nada.

Está claro que lo que Heidegger busca es recuperar la experiencia griega del ser y a esto lo llama pensar. No cabe duda de que en sus motivaciones explícitas están todas aquellas que tienen que ver con un fenomenológico renacer a aquel pensar no preso en los entes. Entre aquella experiencia filosófica de primer orden y esta decadencia de la razón en la maquinación calculadora, el ser ha seguido destinándose al ser humano. Algo tendrá entonces que decir toda esta historia (del ocultamiento) del ser, toda esta manera de ser olvido del ser. Volver a esta historia (en ese proceso de superación y deconstrucción) es la dirección que ha de tomar la tarea del pensar una vez certificado el final de la filosofía, el agotamiento del modelo del pensar técnico-metafísico-científico-positivista.

Pero, a nuestro modo de ver, aquella experiencia griega del ser tiene que confrontarse con algo que los griegos no pudieron siquiera prever: cómo iba a ser una civilización volcada en su poder sobre los entes, y cómo la cultura terminaría siendo fruto de la correlación entre el ser que se destina como olvido y el ser humano que, tergiversando su esencia, acabaría olvidando el olvido. Y es aquí donde yo creo que la experiencia de la mística

indagado con los instrumentos puestos a punto por la fenomenología husserliana, y un sentido de actuación (Vollzugsinn) relativo a la tonalidad emotiva o a la temporalidad dentro de la cual tienen lugar los contenidos y las referencias. Cfr. p. 17.

${ }^{53}$ Cfr. Heidegger, M., GA 15, Frankfurt am Main, Vittorio Klostermann, 2005, p. 363. 
ofrece un modelo para el pensar que Grecia, por razones obvias, no le puede ofrecer a Heidegger. Los primeros trabajos sobre la mística medieval y sobre la fenomenología de la religión querían ser un primer atisbo de lo que el cristianismo primitivo entendió por facticidad, por una existencia en el mundo que se sabe cierta de una posibilidad final que está de algún modo ya siempre adviniendo en esa expectativa escatológica. Aquel modo de vida de la parousía ponía al de Messkirch sobre la pista de hasta qué punto la fenomenología debía acceder al cómo del vivir una existencia que se sabe teniendo que ser en el mundo sin poder acatar sin más la lógica del mundo. La economía salvífica disponía al hombre para un modo de vida que incomodaba; para una sabiduría que para el mundo era necedad o escándalo; y también para un redescubrimiento de la interioridad que ponía al ser humano en una relación con Dios que terminaba reorientando las otras direcciones para con el mundo desde lo que significaba vivir en la incertidumbre del ya pero todavía no, de la tensión escatológica.

¿Qué queda, sin embargo, cuando a la experiencia del abandono en Dios le sucede la experiencia contemporánea del abandono de Dios? La misma experiencia del pensar meditativo que nace, precisamente, en el tránsito de la ausencia de la indigencia (tal y como sucede en la técnica) hasta la indigencia de la ausencia ${ }^{54}$. Esta indigencia es la que nos recuerda las notas de la experiencia mística que, tal y como mencionábamos en la introducción, es una experiencia de desierto, de nihilidad, de un Dios que siempre brilla por su ausencia. Abandonarse en Dios no constituye un desprendimiento para otorgar después una certeza imbatible. En absoluto. También la experiencia de la fe -Kierkegaard dixit- es una experiencia de abandono, de abismo, de vértigo, de lanzamiento en vacío. De modo que, el pensar propio de los tiempos menesterosos, de los que hablaba Hölderlin, puede fácilmente encontrar en la trayectoria de los místicos el ejemplo de una vida interior que se fundamenta y se fortalece cuanto más resultan desmontadas las certezas exteriores. ¿Por qué no interpretar que ahora es el poeta el que tiene la misión que entonces tuvo el místico? Este experimentó la inefabilidad de lo divino con los lenguajes del mundo; aquel ensayará el otro decir que cabe al pensar libre del tener que decir ${ }^{55}$. Este echó de menos a Dios en la experiencia

${ }^{54}$ Heidegger, M., Beiträge zur Philosophie, Frankfurt am Main, Vittorio Klostermann, 1989, p. 234.

${ }^{55}$ Gadamer en "Ser, espíritu, Dios” p. 171, explica hasta qué punto la tradición teológica puso a Heidegger en la senda de un quehacer filosófico que se resistiera a la tentación de la gramática para soportar así un tipo de penuria lingüística a la que se vio sometido debido 
de una ausencia que es otro modo de presencia. Aquel sabe bien cómo, en una época de entronización del ente, no ha lugar el pensar del ser, porque no cabe otra verdad que la que se muestra en la aparición cuantificable.

La experiencia del pensar, de algún modo, instaura la posibilidad de lo sagrado cuya eliminación resulta evidente en los procesos técnicos contemporáneos precisamente porque, en su lógica productiva y calculística, no cabe la posibilidad de la meditación ${ }^{56}$. La noción de lo sagrado en Heidegger, conviene mencionarlo, tiene que ver con el ámbito en el que el ser al darse, nunca se da del todo ${ }^{57}$. El ser queda siempre en excedencia: su darse es algo así como su retraerse, su aparecer, como su esconderse ${ }^{58}$. La metáfora que quiere dar cuenta de esta comprensión de la verdad del ser es la del Ereignis, la del acontecimiento, la del ahi que muestra su presencia en un aparecer que no puede desentenderse de todo lo que se oculta en su aconte-

a la pregunta por el ser que ya no era el ser de lo ente. Jean Grondin, en uno de sus últimos trabajos, explica que el pensamiento del ser como emergencia estaría presuponiendo la idea del ser como surgimiento originario (ekpheresis) que está más allá del ente y que es indecible (arrheton) tal y como Plotino define el Uno. Cfr. Del sentido de las cosas, Barcelona, Herder, 2018, p. 38. Mariano Álvarez, por su parte, hace suya la expresión aristotélica de que, a pesar de que lo podemos saber sobre Dios es poco, ese poco es lo verdaderamente importante. Cfr. Álvarez, M., Pensamiento del ser y espera de Dios, Salamanca, Sígueme, 1994, p. 160.

56 “ (...) hay que salvar esa naturaleza del hombre. Por ello hay que mantener despierta la meditación.” Heidegger, Serenidad, p. 3

${ }^{57}$ En GA 75, pp. 205-209, Heidegger hace una lectura del poema Otoño de Hölderlin que comienza con el verso: "Das Glänzen der Natur ist Höheres Erscheinen”. Este poema, sostiene Heidegger, fue escrito por Hölderlin antes de su muerte, lo cual concluyó un periodo largo de luz oscura, una noche repleta de misterio, un anochecer que permite un decir tal. A este respecto, Capobianco explica que, en la noche oscura de sus últimos años, Hölderlin pudo ver lo que otros no pudieron y, por tanto, sus últimos poemas son capaces de despertarnos al asombro y a la maravilla de lo extraordinario en lo ordinario. "El relucir de la naturaleza es la más alta aparición". La naturaleza es "lo simple", "lo muy simple" por donde todas las cosas vienen a la presencia. La naturaleza se muestra ella misma ante nosotros pero no como un ente ni como algo en el paisaje. No un ver ordinario o percepción, sino un ver que apenas nos permite entrever el proceso total de despliegue de todas las cosas. La naturaleza es lo divino, lo santo. Ciertamente esto no se refiere a algún tipo de tradición ontoteológica, sino a la physis en cuanto incesante emerger, persistencia, tránsito de todo lo que es. La manifestación del ser (en cuanto relucir, fulgurar, deslumbrar, destellar, resplandecer..) pide de nosotros el maravillarse, el asombrarse así como la humildad por el reconocimiento del límite de todo nuestro decir. Cfr. Capobianco, La vía del ser de Heidegger, pp. 57-71.

${ }^{58}$ A este ámbito de lo sagrado corresponde el otro pensar, el meditativo, el de la Gelassenheit, que no es solo la pasividad del dejar ser a las cosas lo que son, sino el hacer (que ya está incorporado en la etimología del verbo lassen) que las cosas sean, en comprometerse con promover que las cosas sean aquello que tienen que ser, que generen espacios, que abran sus posibilidades más propias... Cfr. Chillón, Serenidad. Heidegger para un tiempo postfilosófico. 
cer, en su venir a la presencia ${ }^{59}$. Y entender esto es descubrir también cómo el hombre no puede hacerse con el ser porque, en su entregarse, nunca se da del todo, nunca se agota del todo. Reconocer este ámbito de lo sagrado es rechazar que toda la acción humana tenga que venir dada en términos de un hacer en cuanto producir, en cuanto servir, en cuanto degradar.

Nos toca vivir en los tiempos menesterosos, en la noche oscura, en el desierto... nos toca tener experiencia de lo que, desde el modo de pensar occidental, parece no poder experimentarse si no es asumiendo un modo de giro o de salto en el pensar. La inclemencia impide cualquier tipo de esperanza en una atmósfera que provoca que todo viviente sea indigente; la noche oscura, en la que el alma vive en permanente angustia, acaece sin síntomas de ser mero tránsito a la claridad de un nuevo día; el desierto lo inunda todo y, lo que es peor, crece. El sinsentido es evidente ${ }^{60}$. El nihilismo está servido contraviniendo, sólo en apariencia, el pensar de occidente y sus constantes y permanentes ansias de totalidad, ya sea por boca de Parménides, ya sea con Hegel a la cabeza. Y es que, si la filosofía de la identidad es el diagnóstico, el nihilismo acaba siendo el pronóstico. El pensar que puede nacer de aquí, en cuanto se sabe teniendo experiencia de esa penuria, invita a una profunda cercanía en la que resuena el eco del ser ${ }^{61}$. El eco que se oye cuando no hay nada que (merezca la pena) escuchar. El eco que es la constatación para el otro pensar acerca de cómo aquí, en el silencio más extremo, se barrunta lo que siempre el ser tiene que decir. El ser sigue hablando en

${ }^{59}$ Heidegger expone la fertilidad de la metáfora, fundamentalmente, en El origen de la obra de arte, especialmente en el concepto de tierra que, en palabras de Gadamer, junto a su función privativa y limitadora tiene una función ontológico-constitutiva. "La tierra no es solo lo que los rayos de luz no pueden penetrar. La oscuridad que oculta es igualmente lo que resguarda, desde donde todo irrumpe a la luz, como la palabra desde el silencio". Gadamer, "Ser, Espíritu, Dios", p. 174.

${ }^{60}$ Heidegger ha distinguido, siguiendo a Silesius y a Goethe, entre fundamento como porque y fundamento como porqué. Este último, según explica en Der Satz vom Grund, se refiere a la respuesta en términos de razón suficiente propia de la pregunta por qué. El otro se alza como el "fundamento abismático contra el que choca la pregunta por el porqué, el fundar y el profundizar”. Cfr. Pöggeler, O., El camino del pensar de Heidegger, Madrid, Alianza, 1986.

${ }^{61}$ Heidegger mismo se refiere al pensar del ser como una meditación. Así podemos leer las Palabras conductoras para la meditación del ser: "El ser es lo más vacío y al mismo tiempo la exhuberancia; el ser es lo más común y al mismo tiempo lo único; el ser es lo más comprensible y al mismo tiempo la ocultación; el ser es lo más desgastado y al mismo tiempo el origen; el ser es lo más fiable y al mismo tiempo el abismo; el ser es lo más dicho y al mismo tiempo el acallamiento; el ser es lo más olvidado y al mismo tiempo el recuerdo interiorizante; el ser es lo más coactivo y al mismo tiempo la liberación” Cfr. Heidegger, M., Conceptos Fundamentales, Madrid, Alianza, 2005. 
un silencio difícilmente audible cuyo rumor, el de lo divino, sin embargo, nunca se extingue del todo. La apariencia de esta sordina del fundamento deja toda la realidad repleta de cosas, es decir, tal y como está, pero vacía de sentido en la medida en que lo ente se piensa sin contar con que toda su densidad deriva del peso del ser que está oculto.

\section{Conclusiones}

Sin embargo, todavía hay una oportunidad. La oportunidad está dada para aquellos que, en el modo exhaustivo de lo técnico, perciben la manera en la que el ser está diciéndonos algo, está destinándosenos. Y entonces, en este final del pensar de la totalidad, en esta ilustración exhausta, en esta metafísica perfecta y consumada, hay que volver a donde el ser humano encontró siempre su sentido sin el amarre del mundo, sin la seguridad de las cosas, sin la salvación del poder ${ }^{62}$. Ahí es donde Heidegger, según he intentado sostener, pudo percibir el magisterio incólume de la mística cuya dinámica puede entenderse desde la experiencia vital de tendencia a lo trascendente con la consiguiente relativización de todo lo inmanente ${ }^{63}$. Es probable que sea exagerado sostener con Löwith que la filosofía heideggeriana sea teología encubierta (verkappte Theologie). Sin embargo, tener que descubrir la luz en medio de la sombra, vivir en la dependencia o dejarse en Dios, volverse cara a uno mismo para poder encontrarse, o experimentar la necesidad de devolver el papel protagonista a lo absoluto y el secundario a todo lo relativo, son indicadores de lo que Heidegger quiso decir con el pensar pensante, con el pensar meditativo, cuya tarea es tanto más urgente cuanto más en evidencia queda "que hoy, sin embargo, todavía no pensamos" ${ }^{64}$.

${ }^{62}$ Ortega piensa que ahí estuvo siempre la filosofía, en la retirada, en el arreglo de cuentas consigo mismo en "la pavorosa desnudez de sí mismo ante sí mismo". Ortega y Gasset, J., El hombre y la gente, Madrid, Alianza, p. 106.

63 "El motivo de la mística en la historia absoluta como preparación de la fides. Realización de la humilitas por medio del desasimiento. La mística dio a Lutero un mundo de las experiencias interiores y le mostró también el camino para obtenerlas y acrecentarlas. Por eso el motivo de la humilitas no puede influir solo de modo inhibitorio en el desarrollo alegre y seguro de la fiducia. La humilitas, la tribulatio, se convierten incluso en expresión de la certeza personal de la salvación". Heidegger, M., "Fundamentos filosóficos de la mística medieval”, p. 164.

${ }^{64}$ Heidegger, M., Qué significa pensar, p. 17. Se trata de las lecciones de Friburgo de 1951-52 en las que se aclara que esta falta del pensar no se debe a que los hombres no se dirijan suficientemente bien a aquello que da que pensar, sino al hecho de que lo que merece ser pensado se aparta de nosotros, se ha apartado desde hace tiempo sustrayéndose de una manera tal que, sin embargo, le hace conservar una peculiar e incomparable cercanía. 


\section{Bibliografía}

Agamben, G., El tiempo que resta, Madrid, Trotta, 2006.

Agustín de Hipona, Confesiones, Madrid, Biblioteca de Autores Cristianos, 1996.

Álvarez, M., Pensamiento del ser y espera de Dios, Salamanca, Sígueme, 1994.

Berciano, M., "Esperando su venida. Comentarios heideggerianos de escatología paulina", Naturaleza y gracia, 2-3, 2000, pp. 429-459.

Capobianco, R., La vía del ser de Heidegger, Madrid, Guillermo Escolar, 2020.

Capelle Dumont, Ph., Filosofía y teología en el pensamiento de M. Heidegger, México, FCE, 2012.

Caputo, J., The mystical element in Heidegger's thought, New York, Fordham University Press, 1986.

Casale, C., "La interpretación fenomenológica de Heidegger de la escatología paulina”, Teología y vida, vol. XLIX, 2008, p. 399-429.

Chillón, J. M., "Ser en el mundo sin ser del mundo. Serenidad y direcciones del cuidado en Heidegger", Pensamiento, vol. 74, 2018, p. 661-680.

Chillón, J. M., Serenidad. Heidegger para un tiempo postfilosófico, Granada, Comares, 2019.

De Lara, F., "Heidegger y el cristianismo de San Pablo y San Agustín", Eidos, 7, 2007, pp. 28-46.

Gadamer, H. G., Los caminos de Heidegger, Barcelona, Herder, 2017.

González de Cardedal, O., Cristianismo y mística, Madrid, Trotta, 2015.

Grondin, J., Del sentido de las cosas, Barcelona, Herder, 2018.

Haar, M. "Le moment (kairós), l'instant (Augenblick) et le temps du monde (Weltzeit) en Heidegger 1919-1929", en J. F. Courtine, De l'herméneutique de la facticité à la métaphysique du Dasein, Paris, Vrin, 1996, pp. 67-90.

Heidegger, M., Die Kategorien und Bedeutungslehre des Duns Scotus, GA 1, Frankfurt, Vittorio Klostermann, 1978, pp. 189-412.

Heidegger, M., Beiträge zur Philosophie, Frankfurt, Vittorio Klostermann, 1989.

Heidegger, M., De camino al habla, Barcelona, Serbal, 1990.

Heidegger, M., Serenidad, Barcelona, Serbal, 1994.

Heidegger, M., Los problemas fundamentales de la fenomenología, Madrid, Trotta, 2000.

Heidegger, M., "La pregunta por la técnica" en Conferencias y artículos, Barcelona, Serbal, 2001, p. 9-37. 
Heidegger, M., Introducción a la fenomenología de la religión, Madrid, Siruela, 2005.

Heidegger, M., Qué significa pensar, Madrid, Trotta, 2005.

Heidegger, M., Conceptos Fundamentales, Madrid, Alianza, 2005.

Heidegger, M., Seminare (1951-1973) GA 15, Frankfurt, Vittorio Klostermann, 2005.

Heidegger, M., Seminare (Übungen) 1937/38 und 1941/42, GA 88, Frankfurt, Vittorio Klostermann, 2008.

Heidegger, M., Nietzsche, Barcelona, Ariel, 2013.

Heidegger, M., Estudios sobre mística medieval, México, FCE, 2014.

Husserl, E., La crisis de las ciencias europeas y la fenomenología trascendental, Barcelona, Altaya, 1999.

Ortega y Gasset, J., El hombre y la gente, Madrid, Alianza, 1957.

Pöggeler, O., El camino del pensar de Heidegger, Madrid, Alianza, 1986.

Salviani, C., El oriente de Heidegger, Barcelona, Herder, 2004.

Savarino, L., "La influencia de la interpretación del cristianismo. Arendt y Jonas" en Heidegger y el cristianismo, Buenos Aires, Prometeo, 2017, pp. 177-196.

Savarino, L., Heidegger y el cristianismo, Buenos Aires, Prometeo, 2017.

Sloterdijk, P., La herencia del Dios perdido, Madrid, Siruela, 2020.

Tugendhat, E., Egocentricidad y mística, Barcelona, Gedisa, 2004. 